\title{
REGIONAL INEQUALITIES AND SPATIAL ECONOMIC INTERDEPENDENCE: LEARNING FROM THE GREEK PREFECTURES
}

\author{
S. POLYZOS \\ Department of Planning and Regional Development, School of Engineering, University of Thessaly, Greece.
}

\section{ABSTRACT}

Interregional trade constitutes a major factor of creating spatial economic interdependence. Both within and outside the national borders, spatial economic interdependence can be extremely strong. The interregional trade flows can influence decisively the economic development of each region. They can also formulate the size of the regional multipliers. In this article, the characteristics of spatial economic interdependence among the 51 Greek administrative prefectures are analyzed and evaluated by using the estimations of the regional multipliers. In particular, an interpretation of the interregional inequalities by connecting the interregional multipliers is attempted with certain economic as well as other characteristics of the prefectures of the country.

Keywords: greece, multipliers, regional development, regional inequalities.

\section{INTRODUCTION}

In the last few decades, the varying levels of development observed among the Greek administrative regions and prefectures have certain repercussions on the prosperity of the local communities and on the development of the country as a whole. Therefore, these inequalities constitute a fundamental consideration of the currently applied economic policy. Investigating the magnitude and course of regional inequalities as well as the driving forces that induce unequal development patterns is of great importance in the configuration of an effective regional policy. State intervention towards reducing regional inequalities is considered to be a necessity as long as both the current economic trends and a great deal of empirical evidence reveals the inherent weakness of the market mechanisms for mitigating regional inequalities.

Investigating economic issues on a sub-national level (i.e., regional of prefectural level in the terminology of the present study) requires a different approach in relation to analyzing the same issues on a national level. This is justified, at least, due to the high degree of economic interdependence between the regions or prefectures of a country (as this interdependence is mainly depicted, by the interregional trade flows) in comparison to the degree of economic interdependence between countries. A suitable context for analysis regional differences and interdependencies and for configuring a coherent regional policy can be the use of regional multipliers. The regional multipliers provide a relatively accurate indication of the real size of a regional economy and can contribute to the analysis of the influences to the size of regional economy coming from strategic policy schemes such as public and private investments, structural funds and financial support to regional economic activities.

In two previous studies [1, 2], a multiregional input-output model (MRIO) was constructed and the regional multipliers for unit vector of final demand, consumption vector and investment vector were estimated, on a prefectural level for the 51 Greek prefectures. This was done by using the existing statistical information from National Statistical Service of Greece (NSSG). Subsequently, the regional multipliers were used for simulating the distribution of an extensive investment scheme aimed at achieving convergence of the different levels of development found among the Greek prefectures. In the present article, a further analysis of the regional multipliers' results is pursuit, in order to illustrate some of the critical characteristics of spatial interdependences among the prefectural economies of the country. 
The next section is a synopsis of the way in which the regional multipliers were estimated. Then, it follows an evaluation of both the arithmetic figures estimated for the regional multipliers and the spatial economic relationships or, in other words, the levels of interdependence between the prefectures of the country. In this respect, a correlation analysis between regional multipliers' values on the one hand and the size of the regional economy as well as other regional size characteristics on the other hand is performed. The results are synthesized by means of a cluster analysis and classification of Greek prefectures based on the relative weight of each structural element that the regional multipliers are made up of. The article concludes by commenting on regional inequalities in Greece in the light of the analysis results and by making some wider proposals concerning the currently applied regional policy.

\section{ESTIMATION OF REGIONAL MULTIPLIERS}

The estimation of regional multipliers can be achieved by using the economic base regional model or the Keynensian multiregional model of revenue estimation. Both these models presuppose good knowledge of the economic interdependence that characterizes the regions. Regional interdependence is usually depicted by the interregional trade flows. Another way of estimating regional multipliers is by means of the MRIO. This model provides information about the intersectoral relationships of the economy both in national and regional levels. In MRIO model, each change in the demand for the commodities of a productive sector alters both the output level of the sector and levels of production of the remaining sectors due to sectoral interdependence [3].

Despite certain disadvantages, the MRIO model is considered to be an important "tool" for regional analysis. Compared to other relevant techniques, MRIO model is capable of illustrating in a better way the complex intersectoral relationships within national and regional economies. Furthermore, this model can be used in national and regional economies for planning purposes [3-5]. The multipliers of the MRIO are relevant to the multipliers of the Keynensian model, but they are more accurate and flexible [6]. The estimations acquired by the input-output model are free of the type of analysis-related problems found in the Keynensian model.

The general input-output model is given by the equation:

$$
Q_{n \times 1}=\left(I-A_{n \times n}\right)^{-1} F_{n \times k} i_{k \times 1},
$$

where $n$ is the number of the economic sectors, $Q$ is a column vector of total gross output, $A$ is a matrix of technical coefficients, $F$ is a column vector of final demand and $i$ is a unit vector.

In the case of the MRIO, the general equation is written:

$$
Q_{(m \times n) 1}=\left(I-T_{(m \times n) \times n} A_{n(m \times n)}\right)^{-1} T_{(m \times n) \times n} F_{(m \times n) \times k} i_{k \times 1} .
$$

Equation (2) can be written as

$$
Q_{(m \times n) \times 1}=B_{(m \times n) \times(m \times n)} T_{(m \times n) \times n} F_{(m \times n) \times k} i_{k \times 1},
$$

where $B_{(m \times n) \times(m \times n)}=\left(I-T_{(m \times n) \times n} A_{n(m \times n)}\right)^{-1} T_{(m \times n) \times n}$.

Each element $b_{r s}(r=1 / m, s=1 / m \times n)$ of the table $B$ shows the increase in production of the sector $s$ after a change of a unit in demand. Namely, $b_{r s}=\partial Q / \partial i$. The change in the output of a region after a unit change in the demand of $s$ will be the corresponding partial multiplier and it will be equal to $m_{r s}=\sum_{s=1}^{n} b_{r s} i_{r s}$. The change in the output of each region after a unit change in demand of all other regions will be given from the total multiplier, which will be equal to:

$$
M_{r}=\sum_{r=1}^{n} \sum_{s=1}^{n} b_{r s} i_{r s} .
$$


The output multipliers for the 51 Greek prefectures have been estimated in the above-mentioned studies [1, 2], by using the existing statistical data. In particular, this has been achieved (a) by employing the national input-output tables for obtaining the technical coefficients and (b) by processing and working out the data from a study by the Ministry of the Environment, Planning and Public Works for calculating the interregional trade flows [7-9]. From this last study, the commercial transactions among the 51 Greek prefectures for all tradable products except services have been calculated.

The dimensions of tables $A, T$ and $I$ in eqn (2) are $m n \times m n=510 \times 510(m=51$ prefectures and $n=10$ productive sectors per prefecture). The "structure" of the vector of the final demand $i$ (having dimensions $m n \times 1=510 \times 1$ for the present research) is of crucial importance for the estimation of the regional multipliers. In the calculations, the unit vectors of final demand that were employed derived from the official statistical data $[10,11]$ These vectors were as follows: (a) the vector $i_{1}$ that resulted from the national consumption vector and the corresponding, in percentage terms, distribution of the demand among the sectors, multiplied by 0.01 ; (b) The vector $i_{2}$ that resulted from the national investment vector and the corresponding, in percentage terms, distribution of the demand among the sectors, multiplied by 0.01 .

The estimations were made under the following assumptions: (a) the demand for consumption or investments is fulfilled by national (internal) market forces and hence, it is not taken into consideration the export demand, (b) the technical coefficients of the multiregional model are the same for all prefectures and (c) for estimating of the trade coefficients, the produced commodities of the 10 productive sectors are divided into tradable and non-tradable once (non-tradable commodities refer mostly to services). (Due to space constraints, the calculations and the final results are not included in this article. However, it is possible for this information to be delivered to the interested reader, via e-mail contact. Relevant inquiries can be made to spolyzos@uth.gr.)

The partial multipliers portray the spatial economic interdependence of the Greek prefectures, while the total multipliers indirectly show the productive autonomy and autarchy that each prefecture possess. The total multipliers also illustrate the competitive advantage of each prefecture in the spatial economic competition. Depending on the prices of multipliers, it is possible to divide the prefectures into two clusters: the cluster of the "privilege" prefectures and the cluster of "non-privilege" prefectures. High multipliers' values in one prefecture indicate that this prefecture will benefit significantly by certain expenditures concerning public investments or consumption, even if the expenditures do not materialize within this particular prefecture. The opposite is the case for the prefectures that the multipliers' values are low.

Before we proceed to the results interpretation, it is worth mentioning that a unit increase in the demand $(1 €)$ in each Greek prefecture due to investments (e.g., construction of new infrastructure) or consumption will cause an increase in the output of each prefecture that can be estimated by adding horizontally the arithmetic figures in the lines of the tables. Thus, the total increase that will be caused in the output of the prefecture of Attiki, by a unit increase in the investments in all other Greek prefectures, will be $8.50 €$. Similarly, the increase in the prefecture of Thessaloniki will be $8.09 €$, in Achaia $3.54 €$ and only $0.82 €$ in the prefecture of Evrytania, $0.86 €$ in Fokida, $0.86 €$ in Lefkada, etc. The content of each line in the tables reveals the origin of the increase in output of each prefecture. Thus, the total increase in the output of the prefecture of Attiki is made up by $1.003 €$ coming from Attiki itself, $0.168 €$ coming from the prefecture of Aitoloakarnania, $0.3518 €$ from the prefecture of Viotia, etc.

It is worth pointing out that the total production in the national level exceeds the total demand of 51 units (a unit in each prefecture). Thus, the total increase in the output due to a unit increase in expenses for investments will be equal to $90.32 €$. This means that there is a national investment 
multiplier of $1.77\left(M_{\mathrm{N}}=1.77\right)$. On the other hand, the total increase in production due to a unit increase in consumption expenses will be equal to $99.48 €$ This also means that there is a national investment multiplier of $1.95\left(M_{\mathrm{N}}=1.95\right)$.

\section{EVALUATION OF THE RESULTS}

In this section a holistic evaluation of the estimations and some useful conclusions concerning inequalities between the prefectures of the country are drawn. The first comment concerns the differentiations in the size of the total prefectural multipliers. The prefectures of Attica and Thessaloniki have the highest multipliers for the two demand categories and therefore, they dominate on the economies of the rest of the prefectures. The prefectures of Achaia, Kavala, Imathia, Korinthia, Evia and Viotia follow with multipliers of a relatively high size. The lowest multipliers are found in the prefectures of Evrytania, Grevenas, Fokida and Lefkada. The remaining prefectures are in an intermediate place, with most unfavorable values to be found in the insular prefectures.

The results provide some clear insights of the regional inequalities and the economic asymmetry in Greece and to some extent give a clear indication of the ability for economic development sustained by each prefecture. A proportional distribution of the public expenses for investments or consumption benefits the prefectures with high multipliers and at the same time worsen the position of the prefectures with low multipliers. Hence, a policy targeted at creating in the long-run condition for convergence in the levels of development of the prefectures needs to allocate the public expenses vice versa to the multipliers of the prefectures.

\subsection{Correlation between multipliers and the prefectures' characteristics}

Following, an evaluation of regional inequalities and an interpretation of the resulted divergence in the values of multipliers calculated by using investment vector will be attempted. This is done by means of estimating the correlation between multipliers values on the one hand and various economic and social indicators on the other hand. We assume that the latter reflects the economic and developmental profile of the prefectures of the country. Firstly, the correlation between multipliers values and (a) the economic prosperity of the prefectures, (b) the per capita gross national product, (c) declared income/resident, (d) the rate of population change in the prefectures for the period 1991-2001 and (e) the percentage of urban population in each prefecture is estimated. We expect positive values in correlation, bearing in mind that high multipliers ensure corresponding level of growth and prosperity, while at the same time they may increase population and urbanization.

The data concerning the first three factors were acquired by another study [12], while the data about the remaining two factors were those of the National Census conducted by the NSSG [13, 14]. The correlation values between the sizes mentioned before are presented in Table 1. Apart from the demographic changes, the rest values confirm the initial expectations. All correlation values are positive and statistically significant in a satisfactory level. The negative relationship between the multipliers and the population changes in the prefectures, despite the low level of significance as it is shown by the values of $t$-distribution, leads to the conclusion that the economic growth did not induce changes in the population on a prefectural level. In addition, the differentiations in the results regarding the use of the two multipliers are not very high. For higher scrutiny and for acquiring an improved understanding of the relationships between the consumption multipliers on the one hand and the prosperity indicator as well as the percentage of urban population on the other hand, we have constructed a diagram (Fig. 1) which illustrates the scatter of the coordinates in a normal orthogonal system.

In Table 2, the analytical results of the correlation between the values of the multipliers and (a) the urban size, (b) the natural resources and (c) the structure of the regional economy by using the 
Table 1: Correlation coefficients between multipliers and prosperity indicators or population sizes.

\begin{tabular}{lccccc}
\hline & $\begin{array}{c}\text { Prosperity } \\
\text { indicator }\end{array}$ & $\begin{array}{c}\text { Per capita } \\
\text { gross domestic } \\
\text { product }\end{array}$ & $\begin{array}{c}\text { Declared } \\
\text { income/ } \\
\text { resident }\end{array}$ & $\begin{array}{c}\text { Change in } \\
\text { population } \\
1991-2001\end{array}$ & $\begin{array}{c}\text { Rate of urban } \\
\text { population }\end{array}$ \\
\hline $\begin{array}{l}\text { Consumption } \\
\text { multipliers }\end{array}$ & $0.282^{*}(0.045)$ & $0.105 * *(0.049)$ & $0.395(0.004)$ & $-0.112(0.434)$ & $0.270 *(0.055)$ \\
$\begin{array}{l}\text { Investment } \\
\text { multipliers }\end{array}$ & $0.277 *(0.049)$ & $0.093 *(0.015)$ & $0.383(0.006)$ & $-0.101(0.479)$ & $0.256(0.069)$ \\
\hline
\end{tabular}

$N=51$; values of significant $t$ in parentheses.

*Correlation is significant at the 0.05 level (two-tailed); $* *$ correlation is significant at the 0.01 level (two-tailed).

relevant participation of the three productive sectors to the configuration of the prefectural gross domestic product (GDP) are presented. Through these estimations we will examine the correlation between the multipliers and some critical economic parameters characteristic of each prefecture. The focus is on examining how each parameter is related in a positive way with the level of development in each prefecture. The data about natural resources were obtained by another study [15], while the data concerning the remaining factors were acquired by NSSG $[14,11]$.

From Table 2, it appears that there are positive values of correlation with high statistical significance between the multipliers and the urban size of each prefecture. This fact, in conjunction with the positive values of correlation between the multipliers and the percentage of urban population, leads to the conclusion that developed prefectures are those having large urban concentrations. In addition, the results in Table 2 indicate that both the abundance of natural resources and the level of development in the primary sector do not have a positive correlation with the total level of economic development in each prefecture. It appears that the relative specialization of the prefectures in the secondary and tertiary sectors influences in a larger extent their economic growth than the specialization in the primary sector. For better scrutiny of the results, Fig. 2 presents the scatter of the multipliers' coordinates and the participation of the secondary and tertiary economic sectors in the prefectural economy.

Table 3 illustrates the analytical results of the correlations between the multipliers and (a) the direct or self-population potential (DP) (b) the indirect population potential (IP), (c) the quality of population, (d) the productive strength and (e) the per capita private investments. The direct and the indirect population potentials are indicators of the population agglomerations in each prefecture and of the total accessibility of each prefecture in relation to the other prefectures. These two figures were estimated by using the formulas $D P_{i}=P_{i} / d_{i i}$ and $I P_{i}=\sum_{j}^{n} P_{j} / d_{i j}$, respectively, where $P_{i}$ is the population of prefecture $i$ and $d_{i j}$ represents the distances between the prefectures $i$ and $j$.

The term "quality of population" refers to the general characteristics of human capital in each prefecture and it is related with aspects such as the level of education and the professional skills and specialization of labor force. The level of education, the professional skills and the specialization of a region's population determine the effectiveness of the labor force and thus the degree of competitiveness sustained by the local economy. The data used in the estimations were taken by another study [16]. 
(a)

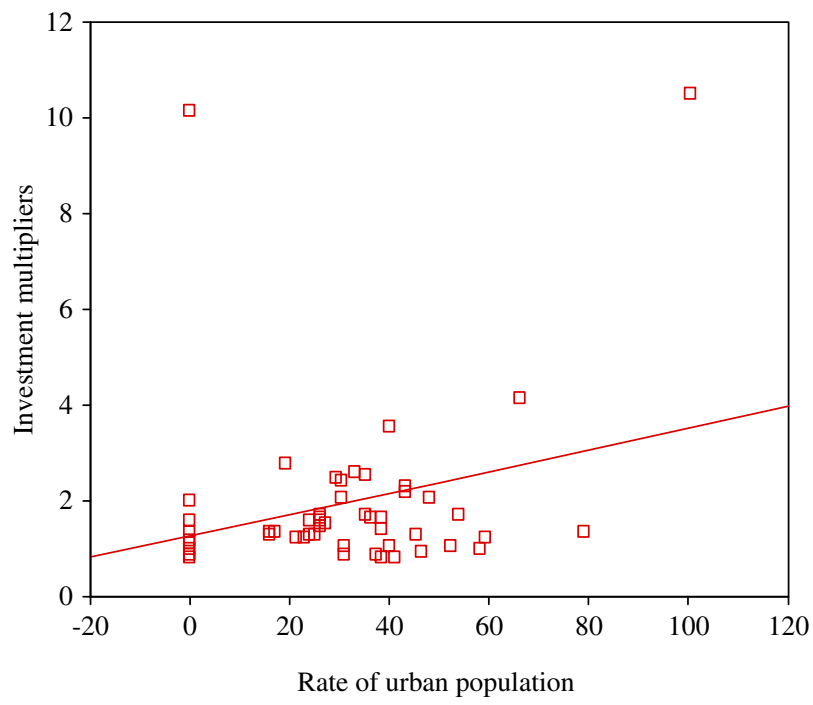

(b)

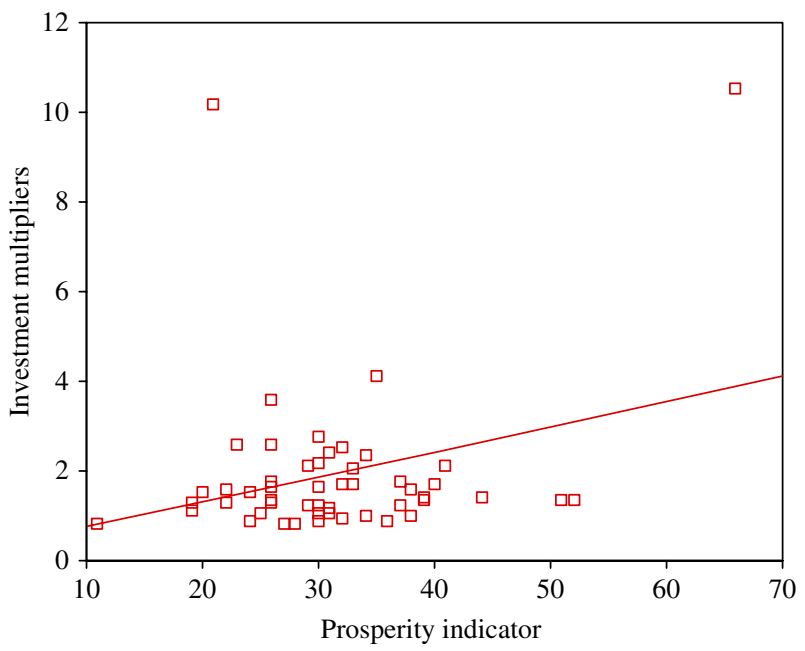

Figure 1: Representation of the relation between the investment multipliers and (a) the rate of urban population and (b) the level of prefectural prosperity.

For estimating the "productive strength" for the period 1991-2001, an aggregate indicator of (a) the average productivity of the prefectures, (b) the average change in GDP and (c) the change in employment level has been created [17, 18]. Improved productive strength is a precondition for having economic growth in a region and it is also an indicator of the region's competitive ability. Finally, the chance of having a correlation between the multipliers and investments having in mind that the private investments influence to some degree the economic growth in each prefecture is investigated. The data about the private investments refer to the period 1991-1997 [19].

The results in Table 3 show that there are positive correlations between the multipliers and all the basic economic factors mentioned before. In particular, the factors "direct population potential" and 
Table 2: Correlation coefficients between multipliers and natural resources or economy's structure.

\begin{tabular}{lccccc}
\hline & Urban size & $\begin{array}{c}\text { Natural } \\
\text { resources }\end{array}$ & $\begin{array}{c}\text { Primary } \\
\text { sector }\end{array}$ & $\begin{array}{c}\text { Secondary } \\
\text { sector }\end{array}$ & $\begin{array}{c}\text { Tertiary } \\
\text { sector }\end{array}$ \\
\hline $\begin{array}{l}\text { Consumption } \\
\text { multipliers }\end{array}$ & $0.636^{* *}(0.000)$ & $-0.053(0.711)$ & $-0.043(0.762)$ & $0.095(0.508)$ & $0.108(0.449)$ \\
$\begin{array}{l}\text { Investment } \\
\text { multipliers }\end{array}$ & $0.638^{* *}(0.000)$ & $-0.056(0.695)$ & $-0.038(0.790)$ & $0.074(0.607)$ & $0.122 *(0.335)$ \\
\hline
\end{tabular}

$N=51$; values of significant $t$ in parentheses.

*Correlation is significant at the 0.05 level (two-tailed); **correlation is significant at the 0.01 level (two-tailed).

"population quality" present a satisfactory level of statistical significance. Thus, it can be said that there is a positive interaction of a varying magnitude between the multipliers and these factors. Finally, Fig. 3 illustrates the scatter of multipliers' coordinates against the population quality and the direct population potential.

\subsection{Multipliers and geographic distances}

Following, an attempt to link the multipliers with the geographical distances and to investigate their relationships in the light of the concepts of "new economic geography" (NOG) was made. The NOG models, especially those put forward by Krugman [20, 21], Fujita [22] and Venables [23], are general equilibrium models. They assume that in a state of monopolistic competition, the size of a city is determined by the action of centripetal and centrifugal forces. Generally speaking, the process of accumulating economic activities operates under the pressure from a certain mechanism. This mechanism encompasses forces of "affinity" and forces of "repulsion." According to the theory of NOG, the geographic distances in conjunction with the urban or economic concentrations influence the intensity of spatial economic interdependence and the size of regional inequalities. These factors determine the size of centripetal and centrifugal forces. They also configure the spatial distribution of economic activities contributing to regional development.

In central regions (in the case of Greece we assume that such areas are the prefectures of Attiki and Thessaloniki), the centripetal forces or affinity forces constitute the advantages deriving from the fact of numerous coexisting activities in these areas. These advantages include the existence of a large-size market for distributing production, a diverse as well as sizeable labor market, positive external economies, increasing scale returns, better diffusion of technology and innovations, linkages between the enterprises, economies of urban scale, etc.

Contrary to centripetal forces, there are also generated forces of repulsion or else centrifugal forces that push the economic activities to spatial dispersion. Such forces are the "immobile" factors of production, land prices, negative economies, the environmental problems, the problems of urban traffic conjunction, social problems, etc. These forces are usually referred to as "external diseconomies" and characterize the large urban concentrations.

Greece constitutes a typical case where during the 1950s the spatial economic forces operated according to the theoretical models of NOG. This resulted in the creation of vast human concentrations in two urban centers, those of Athens and Thessaloniki. Nowadays, these urban centers are powerful poles of attraction of economic activities and they also sustain the largest part of the country's technical and service infrastructure of national and international significance. 

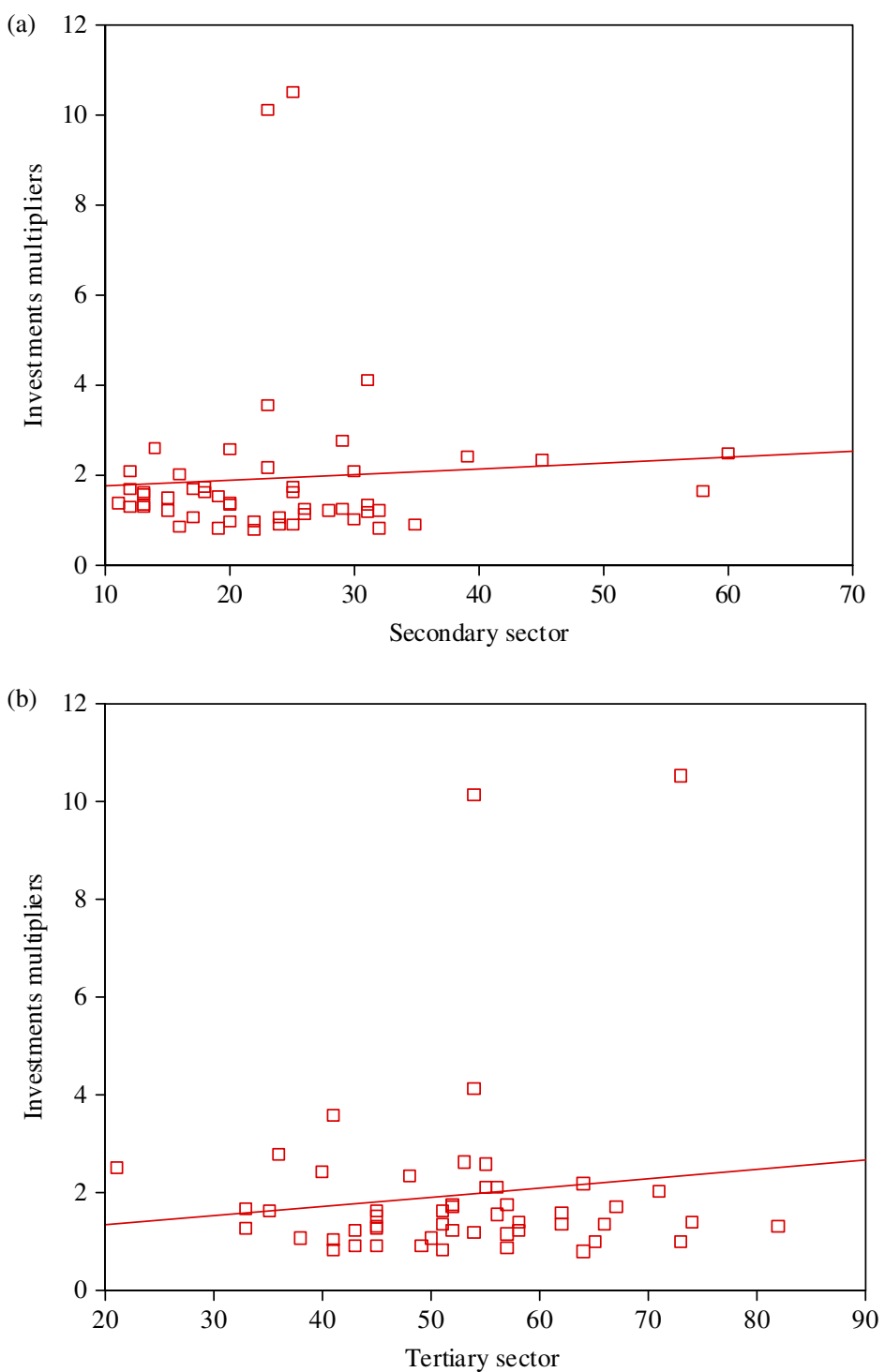

Figure 2: Representation of the relation between the investment multipliers and the rate of (a) the secondary sector and (b) the tertiary sector.

The models used by the NOG attempt to explain theoretically the mechanism of urban evolution and the geographical location of urban agglomerations by means of emphasizing to the determining role of scale returns, externalities and cumulative causation. According to NOG, the transportation cost influences the spatial distribution of markets as well as the system of urban structuring. There is a threshold up to which the firms located in certain regions are allowed to act in a monopolistic environment avoiding competition of firms located in remote regions. Opposition and critics to NOG focus on its theoretical simplifications and on the absence of substantial empirical evidence [24, 25]. 
Table 3: Correlation coefficients between multipliers and population potential or economic sizes.

\begin{tabular}{lccccc}
\hline & $\begin{array}{c}\text { Direct } \\
\text { population } \\
\text { potential }\end{array}$ & $\begin{array}{c}\text { Indirect } \\
\text { population } \\
\text { potential }\end{array}$ & $\begin{array}{c}\text { Quality of } \\
\text { population }\end{array}$ & $\begin{array}{c}\text { Productive } \\
\text { strength }\end{array}$ & $\begin{array}{c}\text { Private } \\
\text { investments }\end{array}$ \\
\hline $\begin{array}{l}\text { Consumption } \\
\text { multipliers }\end{array}$ & $0.606^{* *}(0.000)$ & $0.098(0.496)$ & $0.288^{*}(0.041)$ & $0.149(0.297)$ & $0.022(0.877)$ \\
$\begin{array}{l}\text { Investment } \\
\text { multipliers }\end{array}$ & $0.602^{* *}(0.000)$ & $0.088(0.539)$ & $0.282^{*}(0.045)$ & $0.133(0.351)$ & $0.033(0.816)$ \\
\hline
\end{tabular}

$N=51$; values of significant $t$ in parentheses.

*Correlation is significant at the 0.05 level (two-tailed); **correlation is significant at the 0.01 level (two-tailed).

The relation between transportation cost or else geographical distance and regional development is complex and most of the time blur since many empirical studies have shown that there are many difficulties in determining such a relation [9]. The transportation cost influences the real exchange of products between regions, determines the degree of accessibility for each region and $\kappa \alpha$ reveals the regional comparative advantages. At the same time, it configures the level of spatial competition in a way that a reduction in the transportation cost alters the spatial equilibrium, increases competition and influences the distribution of both people and activities.

In order to investigate the influence of geographical distance to the creation of monopolistic situations in regions taking also into account the total accessibility of each region to the competitive markets, we will correlate the size of the "intraregional output multiplier" of each region with the distances of this region from the two largest, national, economic and population centers, namely Athens and Thessaloniki. The intraregional output multiplier represents a portion of the total multiplier that can be estimated by using the trade flows (or else the trade coefficients) of each region in relation to itself. In essence, these are the elements of the diagonal of the squared table of multipliers $[2,3,15]$. High values of intraregional output multiplier in a region indicate that this region satisfies a significant portion of the demand created within the region. Thus, this region does not depend significantly on other regions as regard economic (or trade) matters.

It is obvious that according to the NOG, the central and remote regions should have high values of intraregional output multipliers. The explanation for this in the context of NOG is possible to depend on two factors: (a) in the case that the region is a central as well as a developed one, it has the potential of satisfying almost any increase in demand with products and services coming from its own firms and (b) in the case that the region is a remote one because of the geographical distance it has the chance of functioning to some degree away from the economic competition of central regions. Thus, a considerable portion of the demand in this region is satisfied from the firms located within the region.

Supposing that if there is large distance between a region and Athens or Thessaloniki, it is possible to get monopolistic situations and then the regions located in medium geographical distances from the two urban centers will present the lowest intraregional output multipliers. Bearing in mind the earlier reasoning, we construct Fig. 4. This figure illustrates the size of the intraregional output multiplier of each Greek prefecture in relations to the time-distance between each prefecture and Athens or Thessaloniki. This illustration assumes that the two urban centers constitute the major economic competitors of the rest of the prefectures. We think that this assumption is fairly justifiable because 

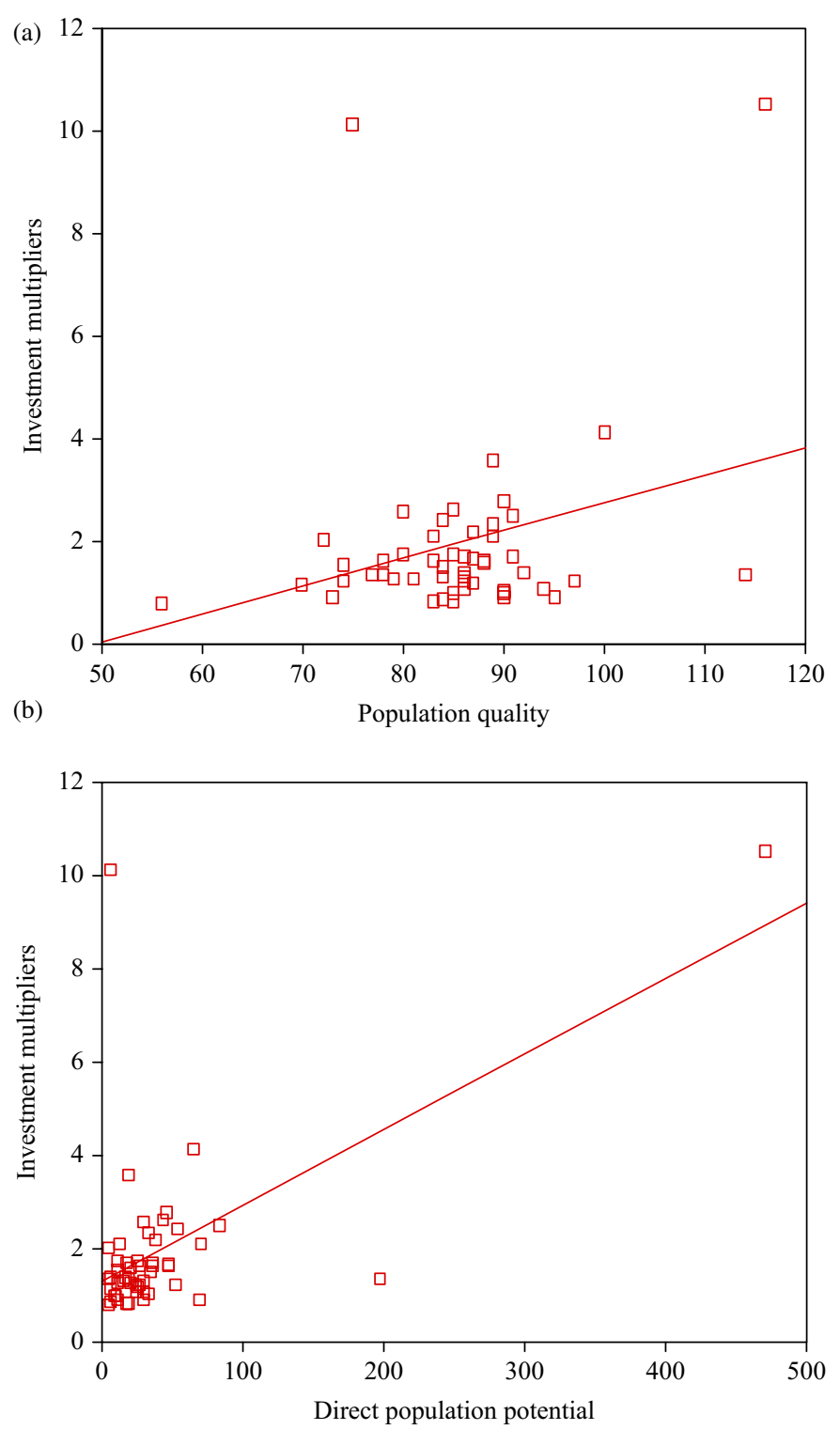

Figure 3: Illustration of the relations between the investment multipliers and the (a) population quality and (b) direct population potential.

if one looks at the direction and the volume of interregional trade flows, they can see that trade matters are dominated by Attiki and Thessaloniki [7, 9].

If we examine the location and the shape of the regression line in Fig. 4, we can see that the theoretical schema of NOG is valid. The prefectures, located close to Attiki and Thessaloniki, have high values of the intraregional output multipliers. In time-distance at about $380 \mathrm{~min}$, the regression line 


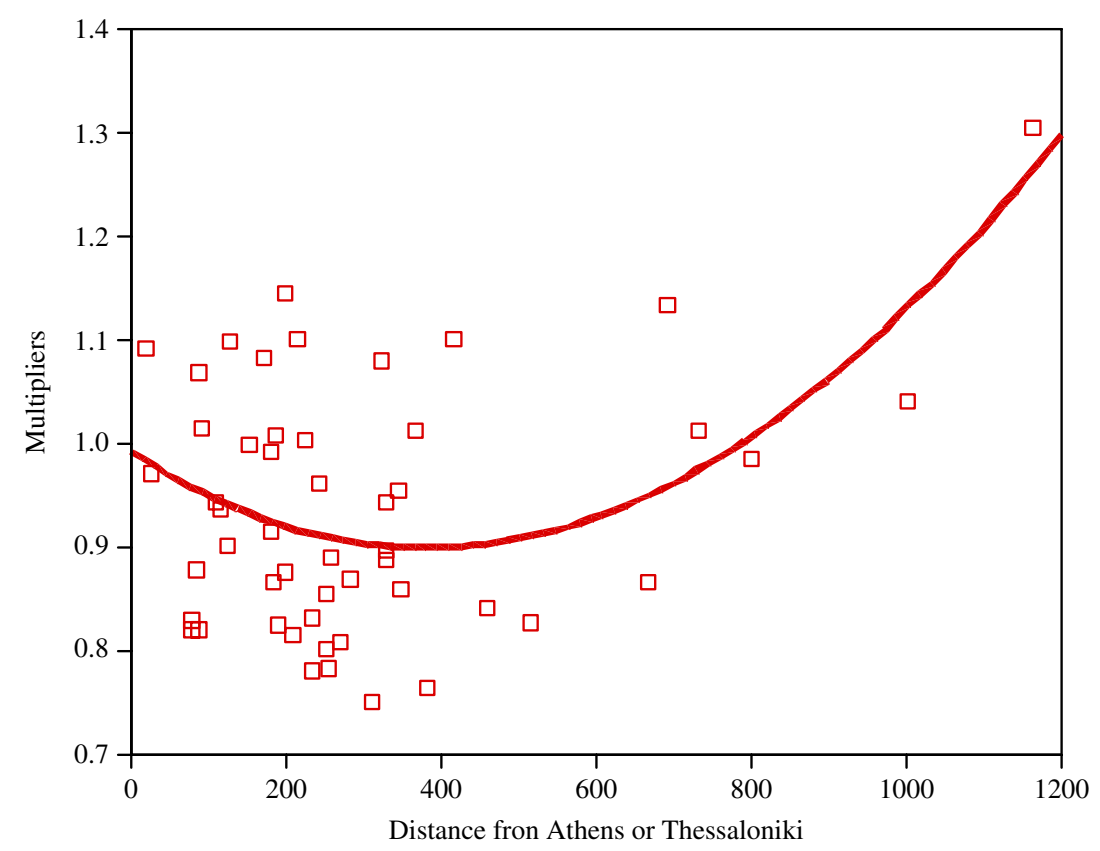

Figure 4: Depiction of the relationship between intraregional output multipliers and the prefectures' distances from Athens or Thessaloniki.

has the lowest values, while in time-distance over $380 \mathrm{~min}$, the values of the multipliers increase. In other words, this time-distance is the threshold level, a sort of safety distance between the prefectures of Attiki and Thessaloniki on the one hand (it could be said that these prefectures are economic "rivals" of the rest of the prefectures) and the rest of the prefectures on the other hand. It is worth mentioning that at this threshold distance are located the prefectures of Arta, Karditsa, Larisa, Magnisia, Evrytania, Fokida, Grevena and Kavala.

The remote prefectures of the country (e.g., the prefectures of Crete, Dodekanisa, Messinia, Ioannina and Evros) are not influenced by Attiki and Thessaloniki as much as the central prefectures are. In other words, they have created a monopolistic environment where the increased transportation cost lowers the level of competing pressure coming from the two major urban centers. Thus, these prefectures have high values of the above-mentioned multipliers.

\subsection{Prefectures greatly depended on Athens and Thessaloniki}

Following, the degree of dependence between all prefectures of the country and the two major urban centers is examined. This dependence is illustrated by the percentage that each prefecture contributes to the configuration of the total multiplier of Attiki and Thessaloniki. The highest dependence on Attiki exhibits the prefectures of Kefalonia (0.53), Korinthia (0.47), Evrytania (0.41), Evia (0,.7), Viotia (0.35) Achaia (0.34) and Fthiotis (0.32). The lowest contribution to the configuration of the total multiplier of Attiki have the prefectures of Evros (0.01), Kastoria (0.01), Florina (0.01), Irakleio (0.022) and Xanthi (0.024). The remaining prefectures are in a medium state. As regards the prefecture of Thessaloniki, the highest contribution to the configuration of the total multiplier has the 
prefectures of Chalkidiki (0.65), Kilkis (0.52), Kastoria (0.45), Pella (0.41) and Pieria (0.38), while the lowest contribution has the prefectures of Crete (Table 4).

Bearing in mind that the distances play a determining role in interregional trade and in configuring of the rates of demand between the prefectures of the country, we consider that the above results are valid as well as expected.

\subsection{Interregional and intraregional differences}

We now turn to the differences between and within the administrative regions of the country. For reason of better scrutiny, Fig. 5 has been constructed. This figure illustrates the distribution of the values of the prefectural investment multipliers per administrative region. The prefectures Attiki and Thessaloniki were excluded.

From the figure we can observe that the regions having the lowest values of the multipliers are the regions of Epirus, the Ionian Islands, the islands of Aegean Sea and Crete. An additional characteristic of these regions is that they have the lowest intraregional differences. The remaining regions include the prefectures with the highest values of multipliers and they have also larger internal differences. The largest intraregional differences can be observed within the regions of W. Greece, Central Greece and Es. Macedonia and Thrace. The first category includes geographically remote as well as insular regions, except Epirus.

We believe that the low values of multipliers in insular areas (these areas have mainly tourismbased economies) do not reflect the real level of prosperity. The estimation of multipliers was performed by using the interregional trade flows of the tradable products. It is apparent that the difficulty in recording and considering non-tradable products such as tourist-related services and the fact that the demand for tourist services mainly derives from abroad have possibly introduced some bias into the multipliers' estimations. Despite this weakness, we think that the value of using the multipliers as a tool for forming regional policy is high.

\subsection{Intraregional cohesion and collaboration}

The major aim of a regional policy is the maximization of the positive results within the targeted regions. These results are depicted in the size of production, the growth of employment and the economic growth. Maximizing the positive results presupposes intraregional economic cooperation. An indication of the level of intraregional economic cooperation can be drawn by the size of commercial exchanges between the prefectures of a region. High values in flows and in the corresponding trade coefficients of I-O analysis for the prefectures of a region result in high values concerning both the output multipliers and the size of production due to an increase in demand in the prefectures of the region. Hence, the intraregional economic and commercial cooperation boosts the multiplied results that derive from an increase in consumption or in investments.

Below, we examine the degree to which each prefecture contributes to the formation of the total multiplier of the rest prefectures of the region. High values of the sum of multipliers indicate that the region is characterized by economic and productive "autonomy." Its production basis is capable of satisfying the needs that derive from an increase in demand within the region. Moreover, bearing in mind that the prefectural multipliers in a region indicate the increase in production of each prefecture after a unit increase in demand of all remaining prefectures in the region, we present an additional dimension of intraregional inequalities.

Figure 6 illustrates the likely changes in production on a prefectural level in four regions if there was a unit increase in investments in each prefecture of the region. The values of the changes in the 


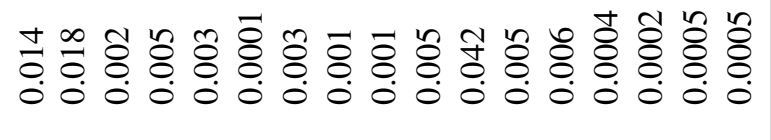

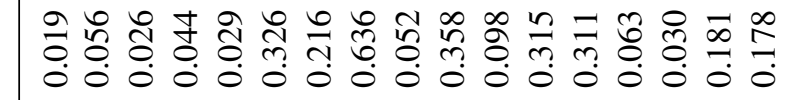

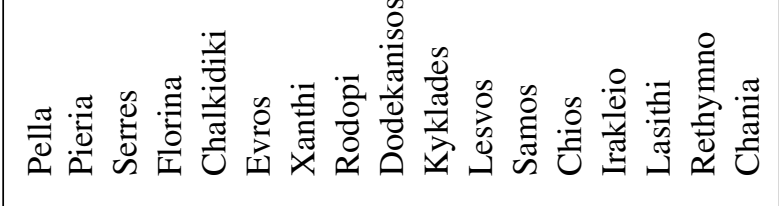

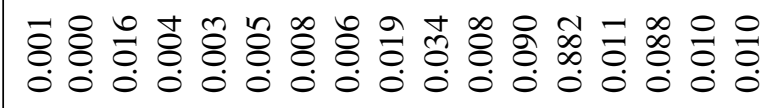

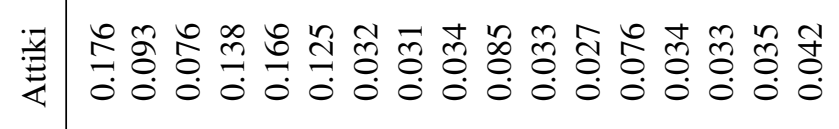

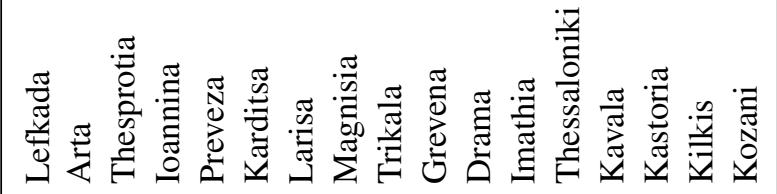

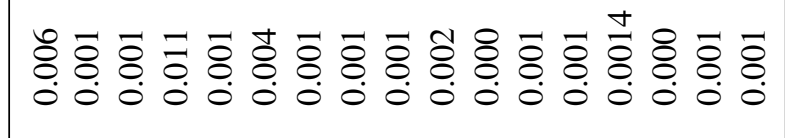

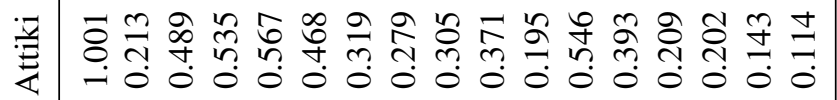

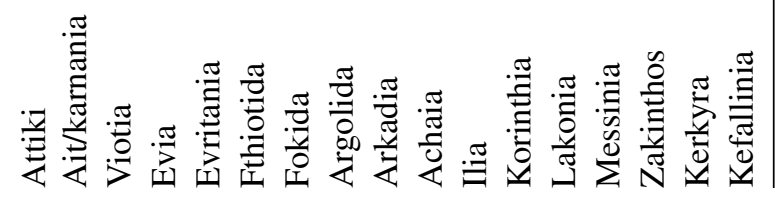




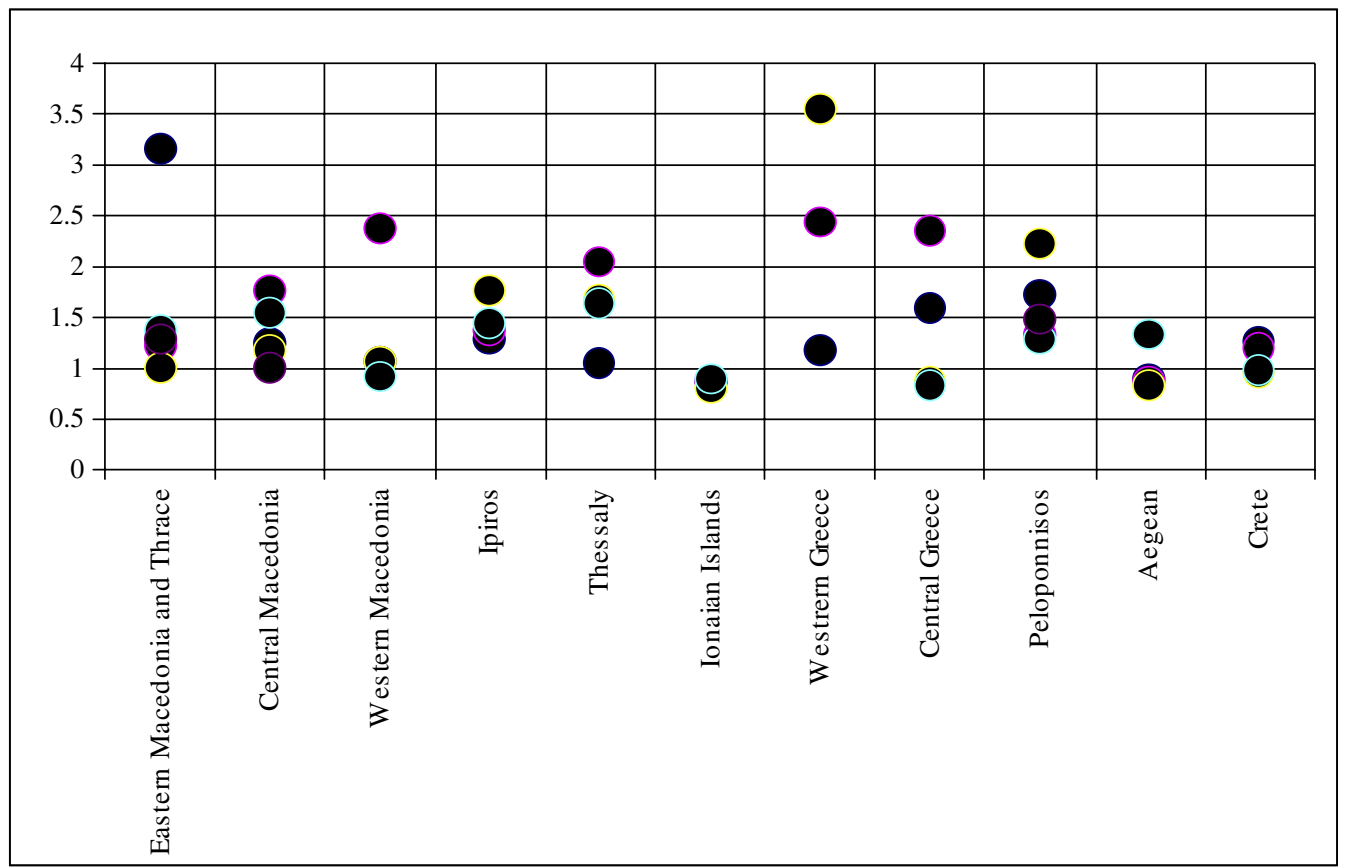

Figure 5: Scatter of the values of the prefectures' investment multipliers per region.

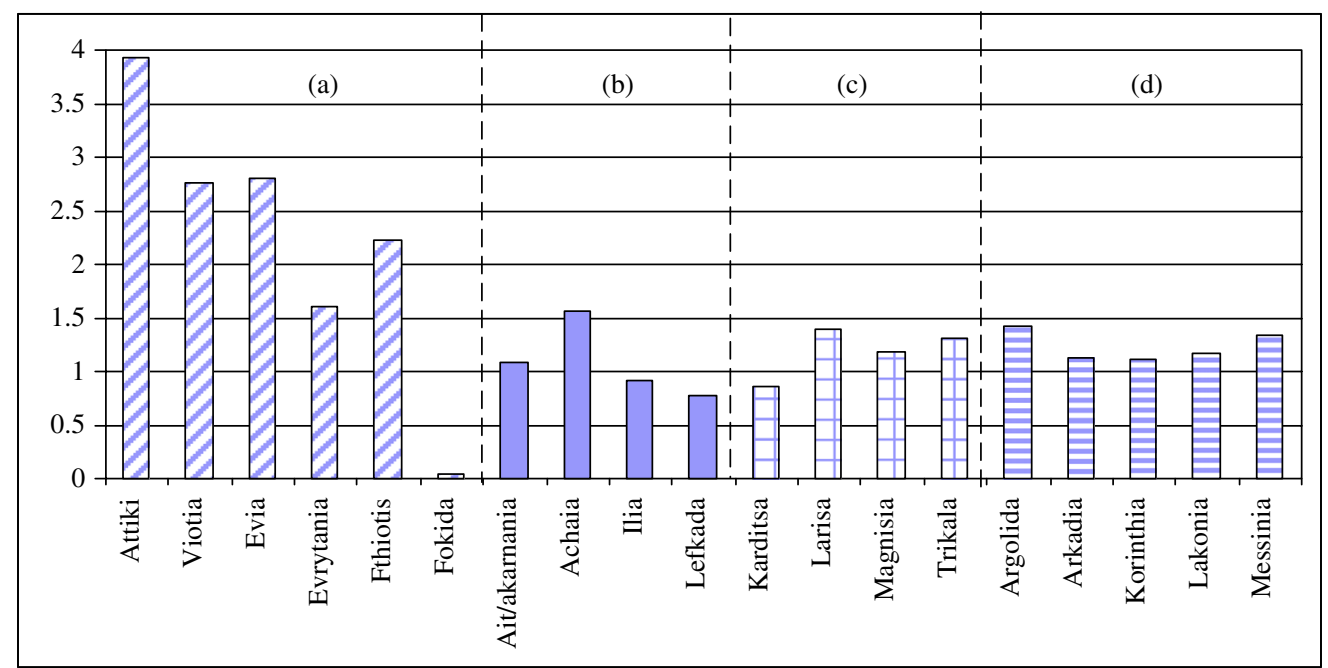

Figure 6: Intraregional multipliers for the regions (a) C. Greece, (b) W. Greece, (c) Thessaly and (d) Peloponnisos 


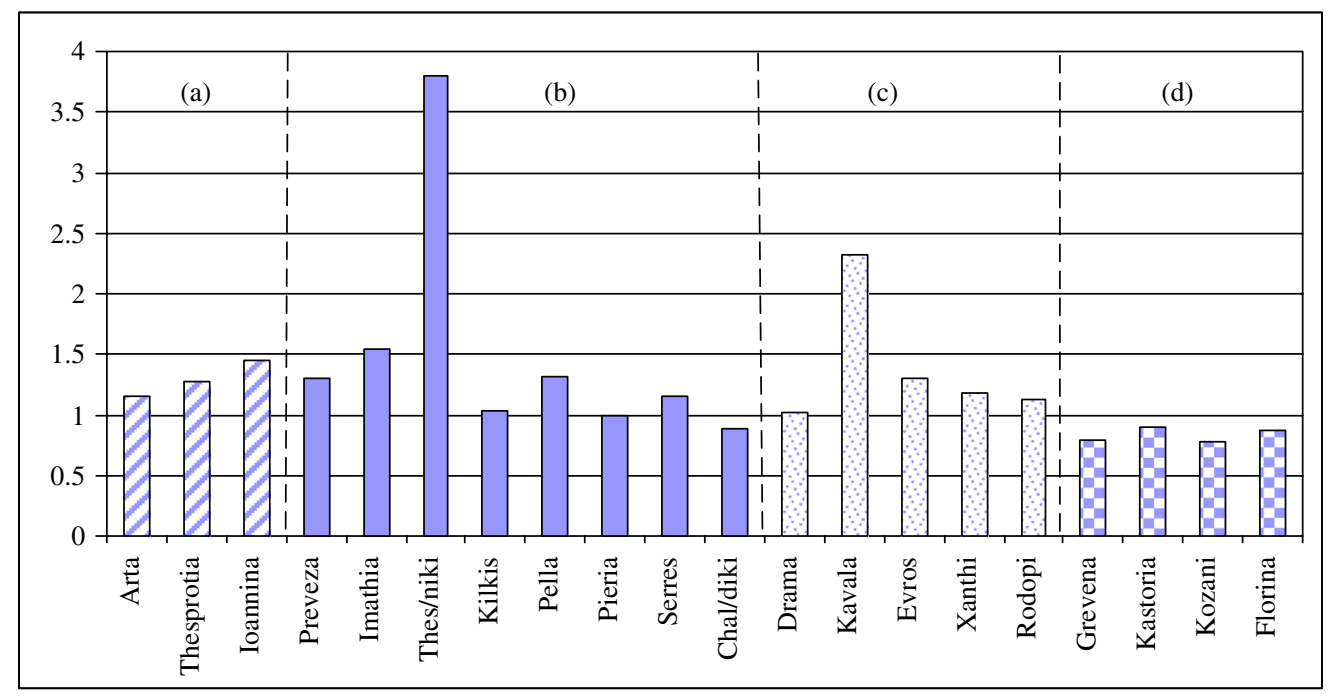

Figure 7: Intraregional multipliers for the regions of (a) Ipeiros, (b) C. Macedonia, (c) E. Macedonia and Thrace and (e) W. Macedonia

prefectural production indicate the effect of the public expenditure towards reducing inequalities within a region. The values of the regional multipliers could be used as a guide for estimating (a) the per capita and (b) the per prefecture corresponding expenditure of a regional investment plan. The proportional distribution of investments (i.e., the same per capita public expenditure in all prefectures) will lead to unequal production levels among prefectures, while a distribution of a vice versa relation with the multipliers will aid, in the long term, in economic convergence.

From Fig. 6, it is apparent that the prefectures of Fokida and Evrytania in the Region of C. Greece and the prefecture of Ilia of $\mathrm{W}$. Greece will benefit less compared to the other prefectures, if a proportional intraregional distribution of public investments is the case. In the Region of Thessaly, we can observe similar inequalities although of a lower magnitude. In the Region of Peloponnisos, the inequalities are even lower.

Figure 7 illustrates the changes in production of each prefecture for four more regions. The prefecture of Lefkada is in a backseat in comparison to the prefectures of Epirus region. On the other hand, the prefecture of Thessaloniki dominates the rest of the prefectures in C Macedonia. A similar pattern can be observed in the case of the prefecture of Kavala in E. Macedonia and in the case of Thrace prefectures, although of a lower magnitude. Finally, in W. Macedonia the values of multipliers of the four prefectures are below unit. This fact shows the region's inability to satisfy the present level of demand. The prefecture of Kastoria is in a relatively better position.

Finally, Fig. 8 presents the changes in the level of production of the insular prefectures of the country. From the figure it results that the Ionian Islands have the lowest economic collaboration and interdependence. This can be explained due to large distances between the islands (the archipelagos covered by this administrative region has a linear shape). The Ionian Islands have higher collaboration with the mainland prefectures of Epirus and the region of western Greece. As regards the island of the Aegean Sea, the patterns observed as somewhat different compared to the patterns of the Ionian Islands. The differentiation is more profound in the case of Crete, where the large distances 


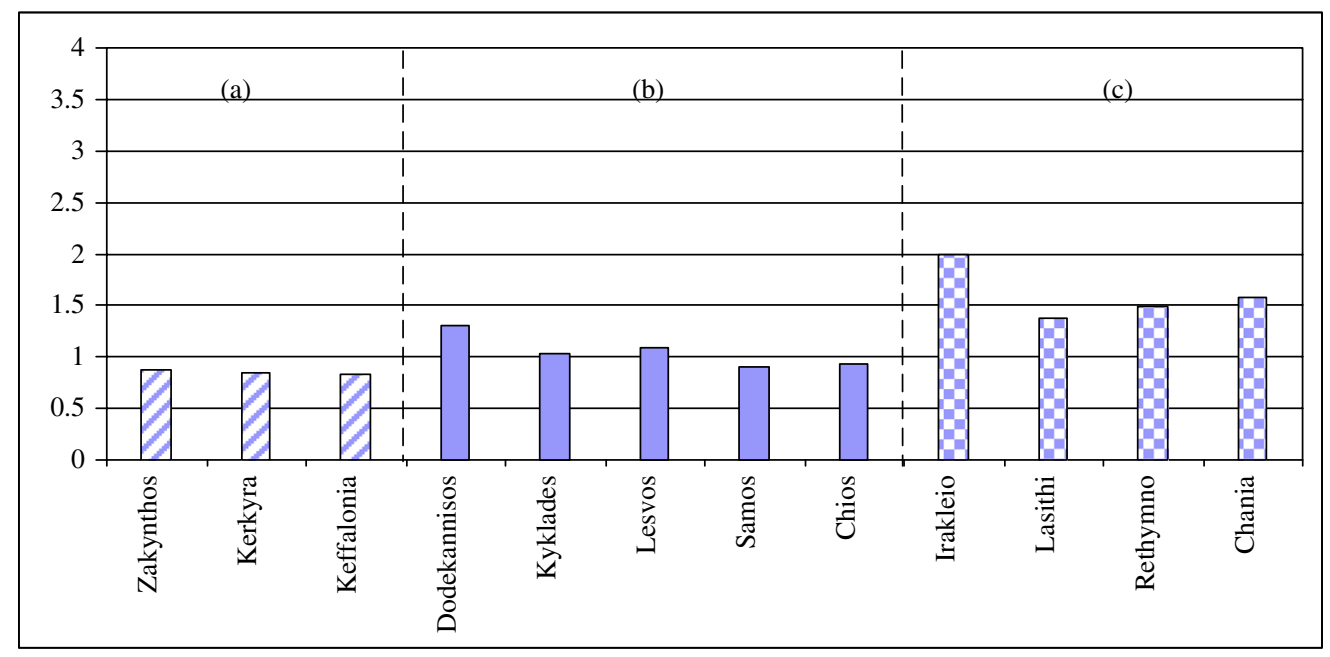

Figure 8: Intraregional multipliers for the regions of (a) Ionian Islands (b) Islands of Aegean (c) Crete.

from the mainland country dictate a high level of intraregional economic collaboration. The prefecture of Irakleio in Crete and the prefecture of Dodekanisa in the Aegean Sea are in a better position islands compared to the rest of the prefectures.

\section{CLUSTER ANALYSIS}

Following, a classification of the prefectures in clusters is performed. This is made on the basis of the portion that the partial multipliers of each sector of production contribute to the formation of the total multiplier of each prefecture. The resulted typology contributes to the systemization of the prefectures in relation to their common characteristics and in particular to the degree that each sector of production contributes to the increase of the output. The term of cluster analysis refers to a wide range of techniques, by virtue of which the segmentation of a set of observations or objects into similar subsets can be achieved. The formation of groups/clusters is not simply based on some $\mathrm{ad}$ hoc calculating routines. These groups/clusters are not only based on firm mathematical grounds but also they constitute a kind of intelligent algorithms, the results of which are mainly interpreted by means of particular subjective rules and indexes [26, 27].

In this study, the technique of hierarchical cluster analysis has been employed. The criterion of distance used in the estimations is that of the Euclidean distance. As it was mentioned before, the variables used in the process of clustering are the portions that the partial multipliers contribute to the total multiplier of each prefecture. As it is illustrated in Fig. 9, the analysis resulted in two spatial units/clusters. The first spatial unit/cluster consists of six prefectures (Attiki, Thessaloniki Achaia, Kavala, Korinthia). The prefectures of this group have a common characteristic, namely they all are highly developed mainly in the secondary and tertiary economic sectors. As regards the structuring of the multipliers, this group exhibit high values in the "manufacturing" sector. On the whole, the prefectures of this group have high values of the multipliers compared to the remaining prefecture.

The second spatial cluster consists of the remaining prefectures located in various administrative regions of the mainland Greece. This spatial cluster presents a smoother distribution of the multipliers' 


\section{Rescaled Distance Cluster Combine}

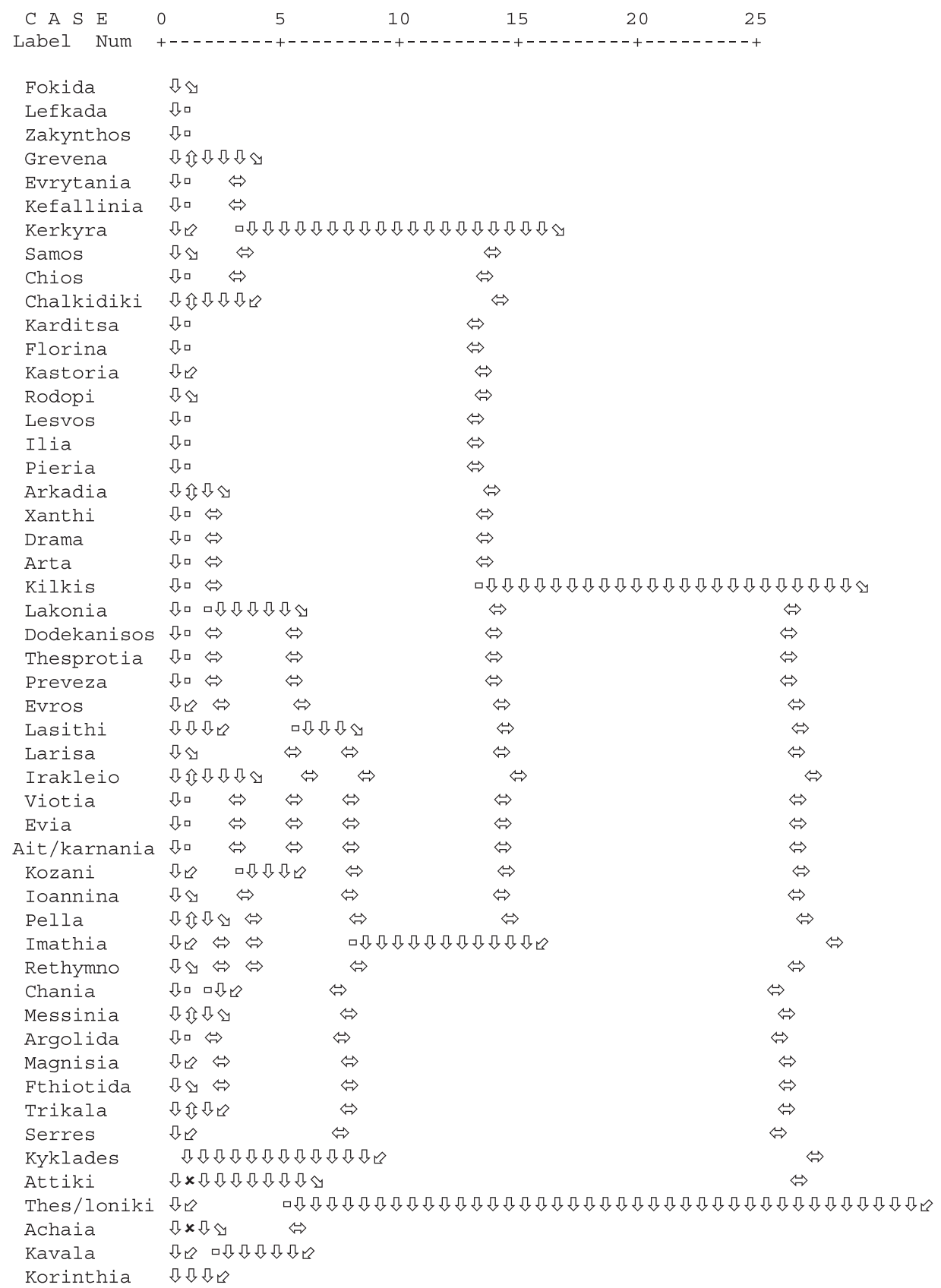

Figure 9: Hierarchical cluster analysis - dendrogram using average linkage (between groups). 
percentages in 10 sectors. Moreover, the second cluster is possible to be divided into two subclusters. According to the dendrogram in Fig. 9, these subclusters have alike distribution of multipliers. In each subcluster, it is possible to find common characteristics in the prefectures belonging to this particular subcluster. The characteristics refer to the size of the multipliers, the size of the prefectures, the level of prosperity, etc.

\section{CONCLUSIONS - PROPOSALS}

As long as regional policy is concerned, the variations in the size of regional multipliers constitute an interesting indicator of the interregional inequalities and of the developmental capacity that each region sustains. Moreover, the insights acquired by studying the regional multipliers can contribute to the formulation of policy which combines effectiveness and spatially balanced development. The main "disadvantage" of multipliers has to do with the difficulty of acquiring the necessary statistical data as well as the difficulty of estimating the multipliers. However, the latter is problem common to almost all technical analysis of regional policies [6]. It is possible to overcome this problem by making the proper assumption and by using special methods for acquiring proxy estimations.

In this article, both an in-depth analysis of the differences in the size of regional multipliers concerning all Greek prefectures and a correlation analysis between the multipliers and various prefectural characteristics and indicators have been attempted. The correlations have led to some useful conclusions about the determinant factors of regional inequalities. Thus, the positive correlations between the multipliers on the one hand and the indicators of prosperity, urban population, degree of specialization of each prefecture in the tertiary sector and "quality" of human population on the other hand led to certain indications about the factors that determine the regional inequalities. In addition, the negative relationship between the multipliers and the natural resources or between the multipliers and the degree of specialization of the economy in the primary sector led to the conclusion that these factors do not constitute comparative advantages for the prefectures that sustain them.

It can be said that the result of the correlation between the intraregional output multipliers and the distances of the prefectures from the two largest urban concentrations are of significant importance. These results constitute an empirical verification of the theoretical schema proposed by the NOG. The large distance between a prefecture and the major urban concentrations influences the level of competition and leads to the creation of a local monopoly with economic and productive autonomy. Additionally, the estimations of the intraregional economic relationships as well as of the interdependence between the prefectures which belong to the same region could contribute to the formulation of solid regional programs towards achieving an effective and balanced regional policy. Every regional development program needs to take into account the intraregional economic interdependence between the prefectures. This interdependence is depicted in the corresponding regional multipliers.

Generally speaking, as long as an increase in the final demand due to certain developmental initiatives in one or more regions spreads out to the other regions, any regional policy needs to take into account the existing spatial economic interdependence $[3,5,28]$. The final proliferative result on the various economic sizes of the region - induced by the implementation of regional policy based on public expenditures - depends on the degree of regional economic "autonomy" as well as on their economic dependence on other prefecture. This dependence is depicted in the size and the direction of the interregional trade flows.

The broadness of the productive basis of a region in productive sectors terms depends on the existence of specialized firms in a variety of sector of production. It also depends on the density of the existing production network and the intensity of the relationships between enterprises. All these 
contribute to the creation of the productive and economic autonomy of each region. The regions with ill, one-dimensional or weak productive basis will benefit to a lesser extent, in terms of local production and employment, by an increase in public expenditures. Moreover, a significant part of their needs are satisfied via trade flows from other more developed regions. The size of final demand satisfied by means of local production creates corresponding proliferative phenomena and it also depicts the extent of economic "dependence" between a particular region and the other regions.

Hence, in addition to the spatial distribution of the economic support, the success of a regional development program is close connected to ability of each region to provide for the additional demand in goods and services by means of internal production or otherwise from the size of the regional multipliers. In other words, the effectiveness of public expenditure as a regional policy tool is limited since some portion of the expenditure goes to the dynamic or prosperous regions, canceling to some extent the significance of the particular policy.

In conclusion, it can be said that the regional multipliers illustrate to a significant degree the size of the spatial interdependence and they also provide an indication about the direction that the planning procedures of allocating public expenditure should follow. Any regional development policy needs firstly to consider the differences in regional multipliers and subsequently to differentiate the distribution of public investments among the regions.

\section{REFERENCES}

[1] Polyzos, S. \& Petrakos, G., The evaluation of regional policy using the regional multipliers. Studies in Greek Economy, eds M. Chletsos, C. Kollias \& H. Naxakis, Editions Pataki: Athens, pp. 269-303, 2005.

[2] Polyzos, S., Public investments and regional development: the role of regional multipliers. International Journal of Sustainable Planning and Development, 1(3), pp. 271-286, 2006.

[3] Miller, R. \& Blair, P., Input-Output Analysis: Foundations and Extensions, Prentice-Hall: New Jersey, 1985.

[4] RIMS II, Regional Input-Output Modelling System, US Department of Commerce, 1981.

[5] Stevens, B., Treyz, G. \& Kindahl, J., Conjoining an input-output model and a policy analysis model: a case study of the regional economic effects of expanding a port facility. Environment and Planning A, 13, pp. 1029-1036, 1981.

[6] McCann, F., Urban and Regional Economy, Editions KRITIKI: Athens, 2002.

[7] Ministry of Public Works/General Secretariat of Public Works, New National Research of Origin-Destination, Athens, 1997 (in Greek).

[8] Polyzos, S. \& Petrakos, G., The influence of interregional highways on the trade: a methodological approach. Technika Chronika II, 20, pp. 47-58, 2000 (in Greek).

[9] Polyzos S., Interregional highways and regional economic changes: a methodological approach. Technika Chronika II, 21, pp. 21-43, 2001 (in Greek).

[10] NSSG, National Accounts Department, Tables of Results of New System of National Accounts for the year, Athens, 1994.

[11] NSSG, Department of National Accounts, National Accounts of Greece, Piraeus, 2005.

[12] Petrakos, G. \& Polyzos, S., Regional inequalities in Greece: literature review and estimations of inequalities. Studies in Greek Economy, eds M. Chletsos, C. Kollias \& H. Naxakis, pp. 185-216, Editions Pataki: Athens, 2005.

[13] NSSG, Statistical Yearbook of Greece, Athens, 2002.

[14] NSSG, Statistical Yearbook of Greece, Athens, 2003.

[15] Polyzos, S., Petrakos, G., Arabatzis, G. \& Soutsas, K., Natural resources and regional inequalities in Greece. Geotechnical Scientific Issues, 6(3), pp. 63-79, 2005 (in Greek). 
[16] Polyzos, S. \& Arambatzis, G., Labor productivity of agricultural sector in Greece: determinant factors and interregional differences analysis, New Medit, Mediterranean Journal of Economics, Agriculture and Environment, 1, pp. 58-64, 2006.

[17] Kavvadias, P., Indicators of Regional Growth of Greece, KEPE: Athens, 1992 (in Greek).

[18] Polyzos, S. \& Petrakos, G., Industrial location in Greece: determinant factors analysis and empirical investigation. TOPOS, 20, pp. 47-58, 2000, (in Greek).

[19] EPILOGI, The Greek Prefectures, Athens, 1998 (in Greek).

[20] Krugman, P., Increasing returns and economic geography. Journal of Political Economy, 99, pp. 183-99, 1991.

[21] Krugman, P., On the number and location of cities. European Economic Review, 37, pp. 293-298, 1993.

[22] Fujita, M., Monopolistic competition and urban systems. European Economic Review, 37, pp. 308-315, 1993.

[23] Venables, A., Equilibrium location of vertically linked industries. International Economic Review, 37(2), pp. 341-359, 1996.

[24] Martin, F., The role of public policy in the process of regional convergence. EIB Papers, 5(2), pp. 69-75, 2000.

[25] Martin, R. \& Sunley, P., Paul Krugman's geographical economies and its implications for regional development theory: a critical assessment. Economic Geography, 72(3), pp. 259-300, 1996.

[26] Hair, J., Andersan, R., Tatham, R. \& Black, W., Multivariate Data Analysis with Readings, 5th edn, Prentice-Hall International, Inc.: New Jersey, USA, 1998.

[27] Sharma, S., Applied Multivariate Techniques, John Willey, New York, 1996.

[28] Polenske, K.R., Leontief's spatial economic analysis. Structural Change and Economic Dynamics, 6, pp. 309-318, 1995. 